\title{
Industrial Composition and Agglomeration Shadow: Evidence from China's Large Urban Systems
}

\author{
Jiaming Li $(\mathbb{D})$ and Dongqi Sun $(1 D)$ \\ Institute of Geographic Sciences and Natural Resources Research, Chinese Academy of Sciences, Beijing 100101, China \\ Correspondence should be addressed to Jiaming Li; lijm@igsnrr.ac.cn
}

Received 14 April 2020; Revised 12 May 2020; Accepted 18 May 2020; Published 30 June 2020

Guest Editor: Wen-Ze Yue

Copyright (c) 2020 Jiaming Li and Dongqi Sun. This is an open access article distributed under the Creative Commons Attribution License, which permits unrestricted use, distribution, and reproduction in any medium, provided the original work is properly cited.

\begin{abstract}
New economic geography (NEG) raises the question why the "agglomeration shadow" effect is significant in some urban regions but not others. This study attempts to answer this question in the context of China by examining the impact of industrial composition of core cities on regional urban systems. Based on the model of urban location from NEG, this study attempts to examine the population growth of six core cities and their urban systems in China. We find services exert a significantly negative effect on market potential, while that of manufacturing is positive. The results are robust in different spatial scales and time spans. This suggests that strong centralizing and agglomerative effects of higher order service sector are more likely to cast an agglomeration shadow on noncore cities in China's regional urban systems. The differences in industrial composition can explain why an urban region centered on a large core city like Beijing is more likely to cast an agglomeration shadow on its surrounding cities compared to the Shanghai-centered urban region. The findings hold important implications for uneven development of regional urban systems and construction of metropolitan areas in China.
\end{abstract}

\section{Introduction}

China is the world's most populous country, and the nation's postreform rapid urbanization has been paralleled by the expansion of a large number of cities. The United Nations report that there were 392 cities with populations of 300,000 inhabitants or more in China in 2014 (https://esa.un.org). Corresponding figures for the United States and India are significantly lower-about 134 and 166, respectively. The high number of cities in China has also resulted in the development of a number of diversified regional urban systems-for instance, the Beijing-Tianjin-Hebei region, the Yangtze River Delta region, and the Pearl River Delta region, which constitute the most rapidly growing regions in China.

Of these three, the Beijing-Tianjin-Hebei region's urban system differs significantly from its counterparts with respect to its development. Beijing has recently failed to boost the development of its surrounding smaller cities. Heavy concentration of resources in Beijing such as communication infrastructure, schools, and hospitals [1] has produced a "poverty belt" of areas around the city. This contrasts with the experience of cities that are near to Shanghai in the Yangtze River Delta region and Guangzhou in the Pearl River Delta region. Second- and third-tier cities have thrived as a result of their proximity to the latter core cities. For example, Shanghai's population is expected to be 30 million in 2020 , but the city has managed to spread its growth around surrounding cities and maintain a reasonable population density [2]. Beijing's urban system for example consists of 38 cities that are mid (1-5 million) and smallsized $(<1$ million) compared to Shanghai which is surrounded by 65 cities of similar sizes.

Under new economic geography (NEG), certain large or core cities will dominate the urban landscape. Such dominance stifles the growth of smaller cities around core cities because the latter casts an "agglomeration shadow" [3]. Beijing's poverty belt for instance captures such a shadow where growth of cities around the capital is impeded because of competition effects. The microfoundation of this phenomenon is provided by Fujita and Krugman [4] using a 
general spatial equilibrium model. But evidence of the presence of agglomeration shadow has also been mixed. For instance, Combes and Overman [5] plotted the spatial pattern of profit per plant in France and suggested that profit decreased gradually with distance from Paris. This implies that the agglomeration shadow around Paris may be negligible. This paper seeks to examine the nature of urban regions in China. Specifically, we seek to examine the influence of industrial composition on agglomeration shadow.

The rest of the article is structured as follows. The next section reviews relevant literature on spillover effect and diffusion mode of industries. This is followed by the description of data and the empirical model. The penultimate section presents the results, and the final section concludes and discusses the findings.

\section{Spillover, Industrial Diffusion, and the Development of Urban System}

The notion of agglomeration shadow may be traced to Alonso [6] who had observed that smaller cities display characteristics of larger cities. Writing about Europe, he noted that urban studies need to consider not only large cities but also smaller ones surrounding the large city that make up the urban system. Smaller cities can benefit from proximity to a large city-they may host fewer functions and goods than they normally would by "borrowing" benefits from large cities (see [7]). Under such a circumstance, agglomeration shadow is absent. However, Burger et al. [8] found that in the case of consumption amenities in Northwest Europe, agglomeration forces may be so strong that they impede the growth of amenities in smaller cities. In effect, their analysis resonates with other authors who argue dominant cities may be hosts to a large number of goods and functions. This adversely impacts the growth of medium and very small cities, creating an agglomeration shadow [3]. In their conceptual study, Ikeda et al. [9] suggested that when agglomeration forces are large, urban systems bifurcate into core and periphery-the periphery in this case potentially capturing the presence of an agglomeration shadow. On the other hand, when urban settlements are connected by industrial belts and agglomeration force is small, then a megalopolis will form as illustrated by the American urban conurbation from Boston to Washington D.C.

Under NEG, an agglomeration shadow is said to develop over time as growth centers industrialize [10]. Prior to this, agricultural production supplies cities with products. As industrialization progresses, geographical forces favor the self-reinforcing dominance of certain cities. Development of these cities occurs at the expense of other cities in the hinterland; in turn, persistence of such a locational structure over time generates an agglomeration shadow. Krugman used Harris' [11] idea of market potential to develop his model. In the model, economic development of a given location depends on its attractiveness for manufacturing, which can be represented by an index of "market potential" derived from the underlying economic dynamics [12]. As firms move away from core cities, the market potential of a given industry shows a nonlinear change. Specifically, as distance to the core increases, potential curve in the hinterland first declines. When agglomeration effects are stronger, market potential rises as dispersion forces dominate. Later in this process, potential curve again shifts, marking a period of decline for more remote areas. The result shows an " $S$ "-shaped relationship between distance to the core and market potential in the periphery in a monocentric urban system. An agglomeration shadow generally exists around places that are not far enough away from a core city [13-16]. Being located closer to agglomeration cores may not always be good news for smaller cities.

More importantly, Krugman [14] has developed a theoretical framework to analyze urban growth and he believes the development of a city in a site is affected mainly by first nature and second nature. Based on this framework and model, empirical studies on the development of the United States' urban system have found some evidence of agglomeration shadows around large cities. For instance, Black and Henderson [17] investigated the evolution of US urban system between 1900 and 1990, based on the Krugman model. Departing from the notion that having large cities nearby could enhance a city's demand and growth potential, they found that positive marginal market potential peters out from the large city, eroding the market of the nondominant or smaller city at some point. Partridge et al. [3] also explored whether proximity to higher-tiered urban centers affected population growth in American counties over the period 1990 to 2000 . Their results suggest that although larger urban centers promoted the growth of cities with fewer than 250,000 persons, agglomeration shadows existed around highest tier metropolitan areas. Using the predictions offered by Fujita et al. [10] and US Census data from 1900 to 1990, Dobkins and Ioannides [18] examined the basic dynamics of spatial interactions among US cities in terms of their populations. Their results confirmed the importance of distance to a higher-tier city for new cities. Such distances were not, however, identified as always being significant for existing cities.

Transportation cost, which has attracted some attention, appears to be a potential factor in influencing urban evolution. Mori [19] simulated the process of US megalopolis formation. The results showed that a megalopolis develops from a number of dense small cities as transport costs of manufactures decreased relative to agriculture. Agglomeration shadows around core cities are too small to be found. Some authors argue that presence of an agglomeration shadow depends on cities sizes: the larger the size is, the more significant will be the agglomeration shadow [20]. Still, it is unclear why some cities cast an agglomeration shadow while such a shadow is small or absent in others. For instance, the populations of both Beijing and Shanghai are quite similar at around 20 million in 2015 (the figures being 20.4 and 23.7 million, respectively), but Shanghai does not appear to generate an agglomeration shadow on its surrounding cities. Transportation cost and population size of core cities may not be sufficient to explain why agglomeration shadows vary among large urban systems.

Indeed industrial sectors have gained some academic attention to the problem of agglomeration shadow. Fujita 
and Mori [21] proposed that inaccurate measurement of market potential and distance may be blamed for the lack of robust results in the study by Ioannides and Overman [20]. However, Krugman [13] has pointed out that the share of manufacturing is important to core-periphery patterns, implying that industrial composition of core cities could be a factor explaining the variation in agglomeration shadows in urban areas. This is because industries that are more differentiated with lower transport costs may result in a larger agglomeration shadow [21].

Whether an agglomeration shadow exists in an urban region may depend on the net impact of positive spillovers and backwash effects of agglomeration cores in relation to surrounding areas. When spillovers are greater than backwash effects, the core is expected to boost surrounding areas. When the reverse is true, an agglomeration shadow develops around the core. Existing studies have paid much attention to test the spillover effect of the core using transport cost. However, some research findings point towards significant differences in the spillover effects of manufacturing and those resulting from the service industries [22-24]. Black and Henderson [17] argued that the development of modern traded services increases urban concentration in the large cities of the United States. Combes [5] has shown that sharp differences exist in the effects of industrial and service sectors on local employment growth.

Although the above studies examined the effect of various economic sectors on spillovers of core cities, relating industrial composition of core cities to the development of regional urban systems remains somewhat understudied, particularly in developing countries like China. Much of the work on agglomeration shadow is concentrated in the United States (US) and Europe. In Asia, Japan has received some attention. For example, Mori et al. [25] found that agglomeration shadows vary among industries in Japan. In his study of the manufacturing and service sectors, Li [26] showed that cities with developed producer services are highly dispersed in China; this distribution contrasts markedly to the geographical concentration of cities with a manufacturing focus. But $\mathrm{Li}$ is interested in the spatial concentration of firms than the impact of industrial composition on agglomeration shadow.

This paper hypothesizes that the industrial composition of core cities positively influences agglomeration shadow and thereby regional urban systems. Information or socially intensive services requiring face-to-face interactions for example in the finance or retail sector are expected to experience higher communication costs [27-29]. In the present context, such costs are part of distance costs that are traditionally modeled as transportation costs. Glaeser and Kohlhase [30] argue that traditional transportation costs are less important in the development of twenty-first century cities. In examining if information risk shapes equity pricing for example, Ghoul and his colleagues found strong robust evidence that equity financing is cheaper when firms are located within 100 kilometers of a major American financial city due to lower communication costs. Zhao et al. [31] also found significant intercore city linkages compared to linkages between core and noncore cities for producer services.
Spillover effect may be smaller in the service sector from hierarchical diffusion, and agglomeration shadow is possibly significant. Indeed the development of producer services in American global cities has strengthened their dominance and control of urban regional systems [32]. On the other hand, while transportation costs matter less in the goods sector today [30], they are small rather than absent. Communication cost is also expected to be lower as linkages between suppliers and customers are facilitated by technology, allowing firms to design regional production networks and manufacturing value chains [33]. Positive spillover through spatial contagion and diffusion may be present in the manufacturing sector, casting a small or absence of agglomeration shadow. Indeed in the case of China, the shift to services in cities, particularly producer services such as finance, has reconfigured previous manufacturing-dominated urban systems. Manufacturing is increasingly dispersed, leaving the coordination and management of urban dominance to service agents. As Yeh and Yang [32] note, this deepens the urban hierarchy with a few dominant cities acting as command and control centers. Interactions within the system are unidirectional and downward from core cities to secondary cities. Fewer horizontal linkages between cities are established as a result. Tervo [34] for instance analyzed the evolution of Finland's cities between 1880 and 2004 and suggested that whilst population centers and their hinterlands grew hand-in-hand in the prewar period, some cities began to cast an agglomeration shadow on their local hinterlands during the postwar period of 1950 to 2004 . He attributed the latter to deindustrialization and the development of service-dominated economies.

Overall, a number of authors point to sectorial changes that need to better capture contemporary urban population movements [35, 36]. Chen et al. [37] also suggested that the gap between theory and empirical reality may have increased as a result.

\section{Study Background and Overview of the Core Cities of China's Urban System}

3.1. Rapid Urbanization in China. Before the economic reforms of the late 1970s, China witnessed a relatively slow rate of urban growth characterized by a low urbanization level that decreased throughout the 1970s. In 1960, the urbanization level was $19.8 \%$. This declined to $17.4 \%$ in 1970 but rose dramatically to $50 \%$ in 2010 [38]. The low level of urbanization is due to the hukou household-registration system, which deterred migration from rural to urban areas. In addition, urban development policies tended to support small cities in order to control the size of large cites [39].

Since 1978, and especially since the 1990s, Chinese cities have experienced a period of rapid development (Figure 1). The urbanization level increased by more than 1 percentage point after the mid-1990s, meaning that each year more than 20 million people joined China's urban population on average [40]. This phenomenal growth in urban population has led to rapid increases in both the number of cities and their size. In line with rapid urbanization, the urban system has 


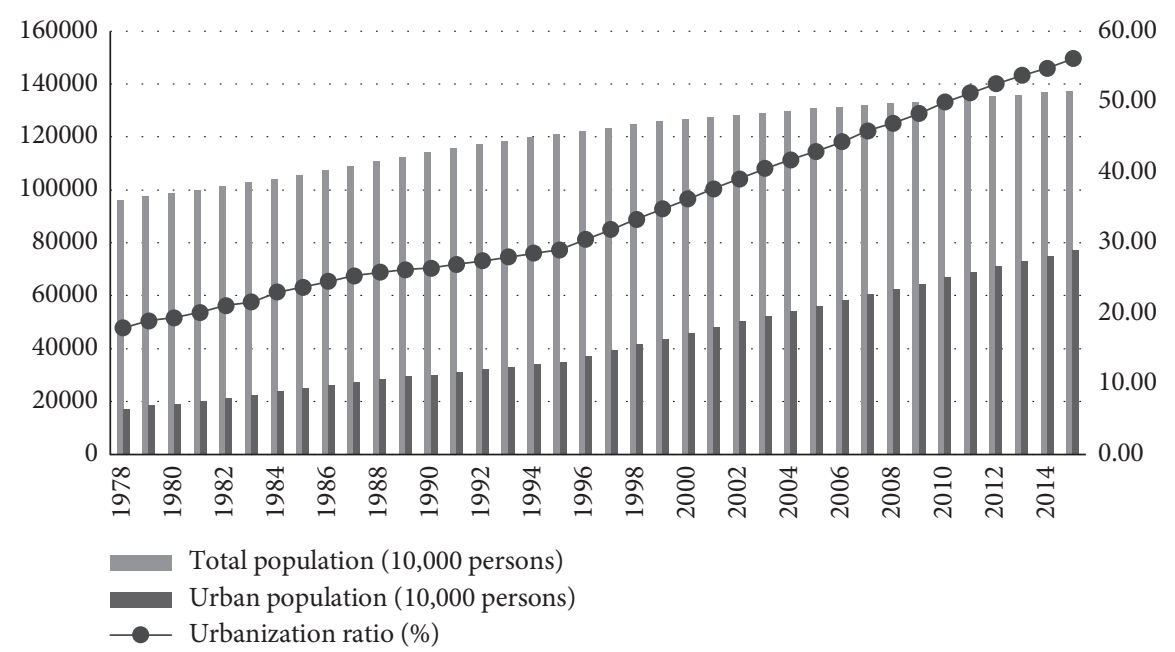

FIGURE 1: Changes in urban population and urbanization ratio in China, 1978-2015.

gradually tended towards a "rank size" pattern in the postreform era [41]. With the dismantling of migration barriers and changes in urban development policies, the urban structure has changed dramatically as a result. Indeed one of the principle changes has been the rise of mega urban regions centered on a few core primary cities leading Chen et al. [38] to ask if China is overurbanizing? Part of largescale urban change is driven by local policy makers' desire to transform primary cities into world stature through control of regional hinterlands and their smaller cities that favors expansion of the service sector, particularly producer services [32].

3.2. Spatial Pattern and Core Cities of the Urban System. Posteconomic reforms and urban development saw the clustering of second- and third-tier cities around a few megacities, which is Beijing, Shanghai, Tianjin, Chongqing, Guangzhou, and Shenzhen (Figure 2). These six megacities had populations above 10 million in 2015 (Table 1). Moreover, the first four cities are municipalities under the jurisdiction of the central government and their administrative levels are equivalent to provinces. The influence these four cities have is at national level. The remaining two cities, Guangzhou and Shenzhen, as China's important foreign trade center and special economic zone, respectively, also have significant impact in south China even whole China, rather than just Guangdong province.

The above six cities are appropriate cases to examine the possibility of agglomeration shadows around large cities, not only because of their dominance in their respective regional urban system but also because of the number of smaller cities that had grown or evolved around them. Although many cities potentially impact other nearby cities, the effects of these mega core cities can be significant. These cities exert influence over other cities around them on account of their huge economies, high market demand, and backward-forward linkages. Take Shanghai for example in Table 2. It is surrounded by more than $100 \mathrm{mid}$ to smaller cities in its urban region including Wuxi, Hangzhou, Suzhou, Yiwu,
Shaoxing, and Ningbo. The Yangtze River Delta centered on Shanghai captures one of the, if not the largest, urban systems in the world.

3.3. Data Collection and Sample. Data for this paper are from the Department of Economic and Social Affairs of the United Nations (UN DESA).The selection of cities (or "urban agglomerations," as described by UN DESA) was made on the basis of cities with 300,000 inhabitants or more in 2015-a criterion that describes about 392 cities in China. The data contain figures for the annual population of these cities, collected every five years, from 1980 to 2015. According to the estimates, populations of the 392 cities have increased rapidly since 1980 and especially since 1990 (Table 1). This trend coincides with China's postreform urbanization process as previously described. The gap between the mean and median size of cities implies that a few cities have maintained very high populations (Table 2). The total population of the six largest cities was nearly 100 million in 2015, a figure which accounts for almost one fifth of the total population of the 392 cities.

\section{Methodology}

4.1. Market Potential. Under the new economic geography, market potential is used to measure the accessibility of different locations to markets. The population and distance are the most essential elements. Although there are other factors (such as wage) that are considered [20], they are mainly focusing on the measurement of market potential. This study is not a conceptual assessment of market potential, and thus using the two essential elements to represent should be enough. Moreover, wage has changed dramatically in China since the reform. The income levels were not comparable.

When calculating MP, certain adjustments have been made in this paper. Firstly, traditional market potential (MP) takes into consideration of all cities in a given nation or region. In this study, we focus on the impact of the six mega 


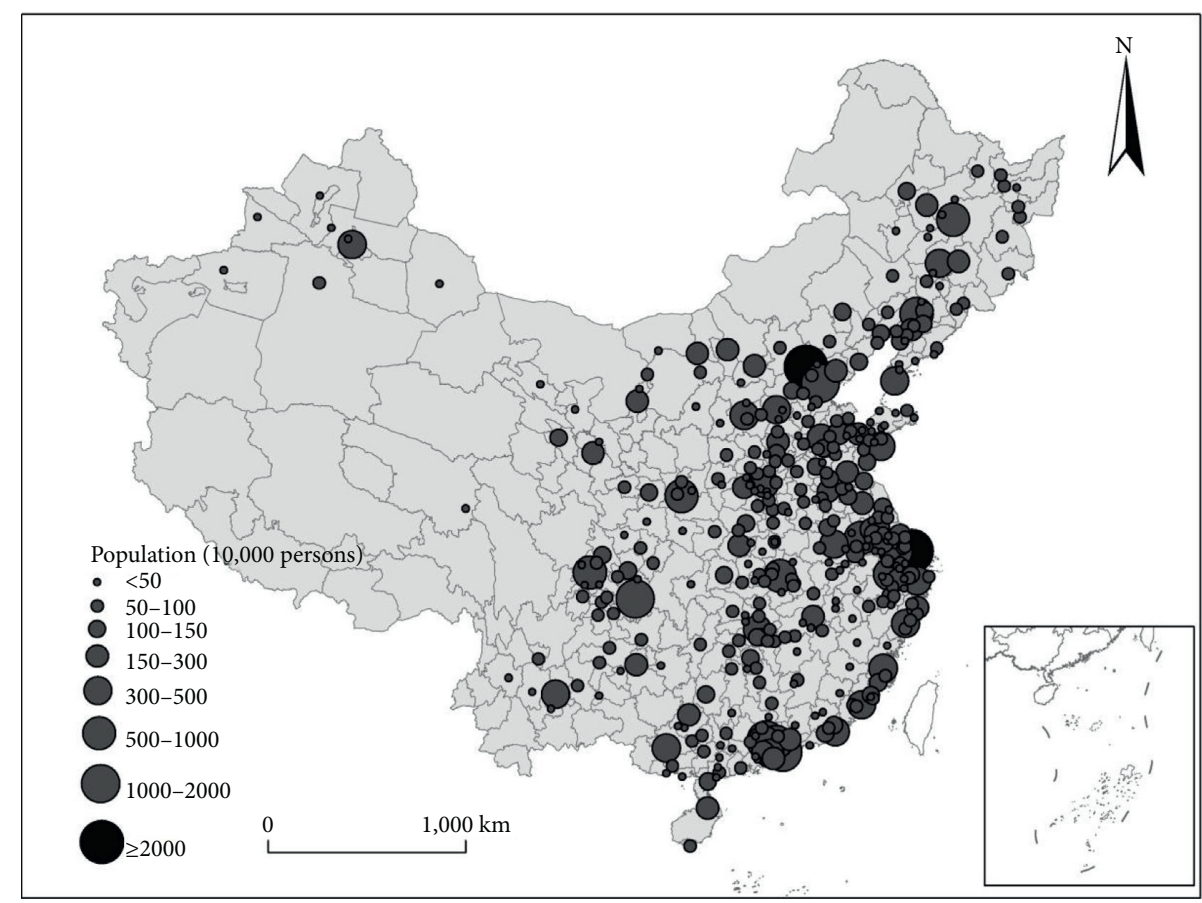

Figure 2: The spatial pattern of urban China in 2015.

TABLE 1: 2015 summary statistics: cities with 300,000 inhabitants or more.

\begin{tabular}{|c|c|c|c|c|c|}
\hline Year & 1980 & 1990 & 2000 & 2010 & 2015 \\
\hline Mean size (thousands) & 276 & 406 & 755 & 1066 & 1248 \\
\hline Median Size(thousands) & 103 & 187 & 372 & 523 & 607 \\
\hline Number of cities with $0.5-1$ million people & 29 & 35 & 79 & 119 & 153 \\
\hline Number of cities with $1-5$ million people & 16 & 32 & 56 & 68 & 86 \\
\hline Number of cities with $5-10$ million people & 2 & 2 & 5 & 10 & 10 \\
\hline Number of cities with above 10 million people & 0 & 0 & 2 & 4 & 6 \\
\hline
\end{tabular}

TABLE 2: Number of cities around six core cities in different periods.

\begin{tabular}{cccccccc}
\hline & & Beijing & Shanghai & Guangzhou & Tianjin & Chongqing & Shenzhen \\
\hline & $1980-1990$ & 138 & 161 & 44 & 5 & 38 & 0 \\
Number of surrounding cities & $1990-2000$ & 129 & 156 & 50 & 3 & 45 & 3 \\
& $2000-2010$ & 126 & 159 & 42 & 1 & 47 \\
& $2010-2015$ & 132 & 155 & 41 & 1 & 45 \\
\hline
\end{tabular}

core cities outlined earlier on small and medium-sized cities around them. As a result, the measure of $M P$ took only the most influential core cities into consideration.

Secondly, it is important to note that "population size" here refers to the average size of selected periods. Because of the relatively long time span studied and the remarkable changes in the size of populations over these periods, measuring market potential by population in the initial year of every period may lead to an underestimation of market potential. In fact, between 1980 and 2015, the population of each of China's six core cities grew by an average of 11.9 million people. On average, this means that each of the country's core cities grew by more than 1.7 million people every 5 years. The rapid increases could lead to inaccuracies in measuring market potential doubtlessly, if the population of only the initial year of each of the time periods is taken into account. MP is calculated city $i$ in period $t$ based on Euclidean distance. The Euclidean distance is not the most accurate measurement for transportation cost, but it is acceptable in the study of macroscale. The formula is as follows:

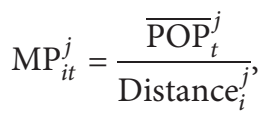

where $\mathrm{MP}_{i t}^{j}$ is the market potential of city $i$ in period $t$ from the core city $j ; \overline{\mathrm{POP}}_{t}^{j}$ is the average size of core city $j$ in the period $t$; and Distance ${ }_{i}^{j}$ is the Euclidean distance, namely, the 
straight-line distances of city centers between city $i$ and core city $j$.

4.2. Regression Models. Based on the model of first nature and second nature [14], we focused on the impact of industrial composition on city growth. The initial year is 1980 and market potential is confined to the "leading force" of core cities that is expected to influence growth of mid and smaller cities in the urban system. China's mid-sized cities can be quite large: the larger cities host between 5 and 10 million people while the smaller ones host between 1 and 5 million people. Small cities are host to less than 1 million people. The effects of industrial composition, we note, may reveal themselves only slowly over time. As such, we included two time periods-5-year blocks and 10-year blocks-in the model, in order to examine both the shortand long-term impact of the industrial compositions of core cities. The most recent 10 -year block spanned only 5 years (that is, 2010-2015). The final regression model is constructed as follows:

$$
\begin{aligned}
\Delta \mathrm{POP}_{i t}= & \beta_{1} \mathrm{POP}_{1980}+\beta_{1} \mathrm{MP}_{i t}^{j}+\beta_{3} \mathrm{IC}_{j t-1}+\beta_{4} \mathrm{IC}_{j t-1}^{2} \\
& +\beta_{5} \mathrm{MP}_{i t}^{j} \times \mathrm{IC}_{j t-1}+\varepsilon_{i t},
\end{aligned}
$$

where $\triangle \mathrm{POP}_{i t}$ is the population growth of city $i$ between time period $t$ and $t-1$; POP $1980_{i}$ is the population of city $i$ in year 1980; $\mathrm{MP}_{i t}^{j}$ is the impact of core city $j$ on city $i$, $\mathrm{IC}_{j t-1}$ is the industrial composition of core city $j$ in time period $t-1$; and $\mathrm{IC}_{j t}^{2}$ is the square of $\mathrm{IC}_{j t-1}$. Existing literature has demonstrated that the impact of industrial composition is nonlinear [42]. As such, we added a square term to the formula. Industrial composition is measured by the shares of industrial added value and service-related added value. To examine the impact of industrial composition on market potential, an interaction variable, $\mathrm{MP}_{i t}^{j} * \mathrm{IC}_{j t-1}$, has been included.

Notably, the core city is the one that exerts the greatest market potential to cities located around rather than the nearest one. In other words, the areas that core cities mainly impact are divided by influence rather than distance. This method has two advantages. On the one hand, for a region with core cities close to each other, the division by the influence is more reasonable than merely considering the distance. On the other hand, market areas are changeable over time which is also in line with the facts. Unlike the other five cities, Shenzhen has not long been a core city in China. So, in the early times of economic reform, it has little impact on surrounding cities. With the development, Shenzhen began to impact more and more cities (Table 2). Moreover, six core cities have powerful influence and are located in north China, south China, east China, and west China, respectively, so we take the whole China as the study area. In spite of this, there should be a certain boundary for one urban system centered on one or two core cities. Bosker and Buringh [43] found the range of influence of cities was about $100 \mathrm{~km}$ in Europe. In this paper, we set $100 \mathrm{~km}, 300 \mathrm{~km}$, and $500 \mathrm{~km}$, respectively, as boundaries to investigate China's urban systems. Besides, we also investigate short-term (5 years) and long-term (10 years) effects of market potential and industrial composition, respectively. Multidimensional analysis and calculation largely compensate for the problem of fewer variables and make the results more robust.

Although the above panel data model is expected to control for factors that are unobserved but remain unchanged over time, this paper focuses on manufacturing and service rather than agriculture for the reason that China's industrial weight is considerable but core cities are also encouraged to join the rank of world cities through cultivation of the service, particularly producer service sector. It should be pointed out that Storper and Scott [44] have argued that human capital may be important in urban dynamics. However, China was also still heavily agricultural in 1980, and human capital was not a significant share of the labor force then. The number of students entering the university was 280,000 , less than $0.03 \%$ of the population in 1980. Moreover, the number of skilled workers is highly correlated to the size of population in Chinese cities. Therefore, using population may still capture some human capital effect among cities in 1980.

\section{Empirical Results}

5.1. Overview. After China's economic reforms, the populations of the six core cities being examined here remained large even as their industrial composition changed dramatically. Shanghai is host to more than 23 million inhabitants and is second only in city size to Tokyo in Asia. Beijing is also one of the largest cities in the world. In 2015, the population of the smallest of China's six core cities, Shenzhen (10.8 million), was nearly 3 million higher than that of the largest mid-sized noncore city-Wuhan (7.9 million). However, the change in industrial composition is evident. On average, the share of added value attributed to the service sector increased from $28.1 \%$ in 1980 to $54.7 \%$ in 2010. In four of the six core cities, the share exceeded by more than 50\% and in Beijing; this figure reached $75.1 \%$, which is nearly $20 \%$ higher than that of Shanghai. By 2010, the manufacturing sector's share exceeded the service industry's only in Tianjin and Chongqing, with shares that were in fact close to $50 \%$. A shift from manufacturing to a service-based urban economy occurred in most of the country's core cities.

While average distance between the closest of core cities is $418.2 \mathrm{~km}$, significant differences exist between them in terms of their proximity to other core cities (Table 3). Likewise, differences exist in the distance between noncore mid and smaller cities and core cities. For instance, Foshan is less than $50 \mathrm{~km}$ from its core city Guangzhou. Other cities, in contrast, are significantly more remote-for instance, Yining, which is located in Xinjiang province, is more than $1,000 \mathrm{~km}$ from its nearest core city Chongqing. In the case of the latter, the impact of core cities is expected to be very weak.

In this paper, the industrial sectors include mining as well. But the presence of mining industry is also negligible in the core cities. While the service sector share is highest in 
Table 3: Descriptive statistics of cities.

\begin{tabular}{|c|c|c|c|c|c|c|c|}
\hline & $\begin{array}{l}\text { Population of } \\
\text { core cities in } \\
2015 \\
\text { (thousands) }\end{array}$ & $\begin{array}{c}\text { Population of } \\
\text { noncore cities in } \\
2015 \\
\text { (thousands) }\end{array}$ & $\begin{array}{c}\text { Share of } \\
\text { industrial added } \\
\text { value in core } \\
\text { cities in } 2010 \\
(\%)\end{array}$ & $\begin{array}{c}\text { Share of } \\
\text { service added } \\
\text { value in core } \\
\text { cities in } 2010 \\
(\%)\end{array}$ & $\begin{array}{l}\text { Population growth } \\
\text { of core cities } \\
\text { between } 1980 \text { and } \\
2015 \text { (thousands) }\end{array}$ & $\begin{array}{c}\text { Population growth } \\
\text { of noncore cities } \\
\text { between } 1980 \text { and } \\
2015 \text { (thousands) }\end{array}$ & $\begin{array}{l}\text { Shortest } \\
\text { distance to } \\
\text { core cities } \\
(\mathrm{km})\end{array}$ \\
\hline Mean & 15312.33 & 1029.23 & 38.37 & 54.74 & 11983.83 & 800.32 & 418.23 \\
\hline $\begin{array}{l}\text { Standard } \\
\text { deviation }\end{array}$ & 4941.09 & 1224.56 & 9.70 & 12.11 & 3401.71 & 963.00 & 379.45 \\
\hline Min & 10749.00 & 308.00 & 19.58 & 36.35 & 7460.00 & -116.00 & 18.24 \\
\hline Max & 23741.00 & 7906.00 & 47.82 & 75.11 & 17775.00 & 7298.00 & 2724.71 \\
\hline
\end{tabular}

Beijing, nearly half of that, at least in terms of employment, is generated by the producer service sector. This is also the case for Shenzhen where producer services account for nearly $45 \%$ of the service sector. Chongqing had the lowest producer service share at $17.8 \%$. Although there is, to a certain degree, a substitution effect between manufacturing and service, in order to obtain accurate and reliable results, their respective impacts were measured separately. We also tested the long-term impact of industrial composition by setting a time period of 10-year blocks. The results of the 5-year and 10 -year blocks may be cross-checked.

\section{Short-Term Impact of the Manufacturing and Service Sectors}

6.1. Manufacturing. The regression results are reported in Table 4. Importantly, when the interaction variable $\mathrm{MP} * \mathrm{IC}_{m}$ is added in model 3, MP becomes insignificant, while $\mathrm{MP} * \mathrm{IC}_{m}$ is positive and significant at $1 \%$. It indicates that the effects of manufacturing share and market potential are in the same direction. The interaction variable $\mathrm{MP} * \mathrm{IC}_{m}$ means the effect of market potential exerted by manufacturing sector is controlled, so MP is the part of market potential of service and agriculture. Due to very few share of agriculture in core cities, the result shows that service has insignificant and even negative effect on market potential. Moreover, the higher the manufacturing share, the stronger the relationship. In other words, manufacturing strengthens the positive effect of core cities' market potential on population growth of surrounding cities, and hence agglomeration shadow is likely to be absent.

Table 4 also shows that manufacturing share $\left(\mathrm{IC}_{m}\right)$ is negative and significant in model 1 , and hence increased manufacturing share results in a fall in population growth of cities in the urban system. When the square term of this variable is introduced to the model, the coefficients of the first-order terms turn positive, while the second-order item coefficients are negative for both fixed and random effects. The two models may point to a significant "inverse U" relationship between the share of manufacturing in core cities and growth of surrounding cities rather than a linear trend.

6.2. Service. Table 5 presents the results for service share. Unlike manufacturing, the coefficient for $\mathrm{MP} * \mathrm{IC}_{s}$ is negative, while MP is positive. The result confirms the finding in the analysis of manufacturing. This would suggest that the expansion of the service sector suppresses the effect of core cities' market potential on population growth, while manufacturing reinforces it. Moreover, the $R$-squared value increased significantly under the random effect model. It may indicate that initial population size matters in the growth of surrounding cities.

When we compare the results of manufacturing, the similarity is that an "inverse U" relationship has also been found between the share of the service sector in a core city and the growth of surrounding cities.

We also investigate the effect of industrial composition in three spatial scales: $100 \mathrm{~km}, 300 \mathrm{~km}$, and $500 \mathrm{~km}$. The results further confirm the different effects of manufacturing and service industries on market potential, the positive effect of manufacturing on market potential while the negative effect of service. It means the effect of industrial composition is stable in different spatial scales. Moreover, we find that the smaller the spatial scale is, the more significant the effect of manufacturing and service is on market potential. However, the "inverse U" relationships between the shares of both manufacturing and service sectors in core cities and the growth of surrounding cities are not stable, especially in small spatial scales. For manufacturing, there is still no significant "inverse $U$ " relationship, and for service, the "inverse U" relationship is also not stable enough, even within $300 \mathrm{~km}$ away from core cities (Tables 6 and 7).

6.3. Long-Term Effects. Long-term effects of industrial composition covering 10-year time periods are reported in Table 8. When interacted with industrial composition, it is positive and significant for manufacturing under the random effect model but negative and significant for service for all three models. This again shows that higher manufacturing share strengthens the relationship between market potential and growth of surrounding cities' population, while the opposite is true for service share. Moreover, for random effect, the coefficient estimates are larger in the models of 10year periods than that in the model of 5 -year periods for $\mathrm{MP} * \mathrm{IC}$. The results show that the impact of industrial composition on market potential does not disappear but even possibly strengthens over time. Nonetheless, the results point to the different effects of industrial composition on growth of urban population around core cities by market potential and their potential to explain the presence or lack of presence of agglomeration shadows. Finally, the effect of 
TABLE 4: Regression results of manufacturing shares, 5-year periods.

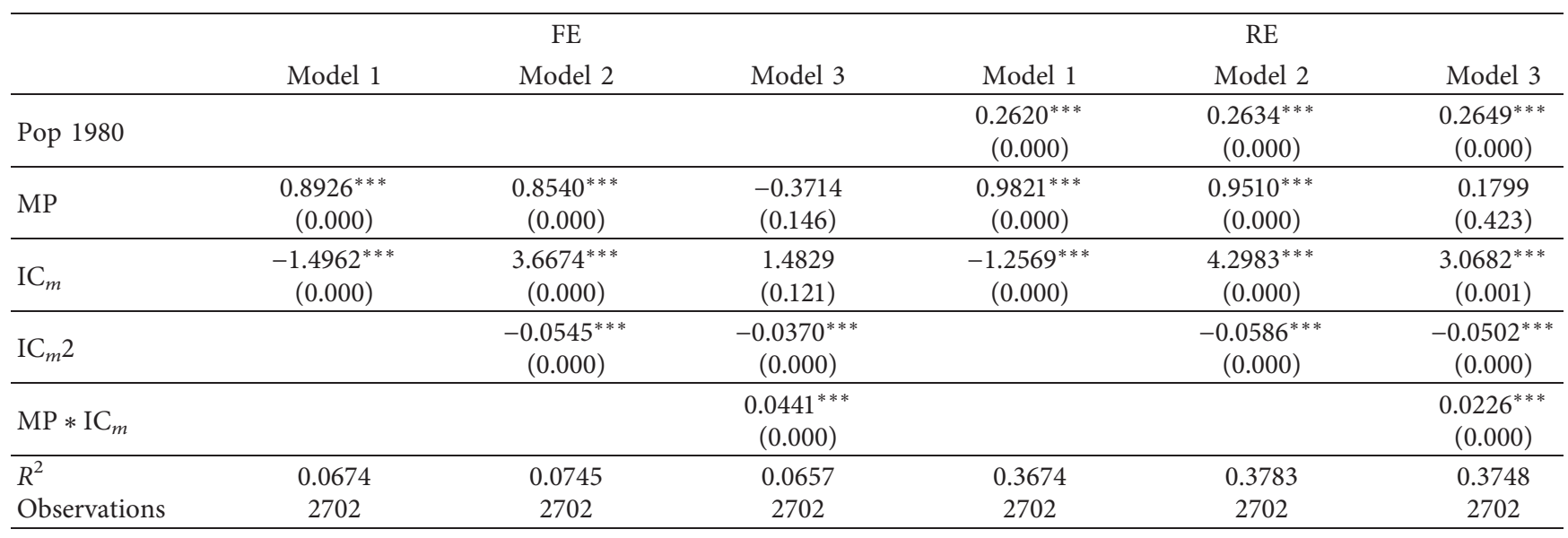

${ }^{*} p<0.1 ;{ }^{* *} p<0.05 ;{ }^{* * *} p<0.1$.

TABLE 5: Regression results of service share, 5-year periods.

\begin{tabular}{|c|c|c|c|c|c|c|}
\hline & \multicolumn{3}{|c|}{$\mathrm{FE}$} & \multicolumn{3}{|c|}{$\mathrm{RE}$} \\
\hline & Model 1 & Model 2 & Model 3 & Model1 & Model 2 & Model 3 \\
\hline Pop 1980 & & & & $\begin{array}{c}0.2630^{* * *} \\
(0.000)\end{array}$ & $\begin{array}{c}0.2651^{* * *} \\
(0.000)\end{array}$ & $\begin{array}{c}0.2671^{* * *} \\
(0.000)\end{array}$ \\
\hline MP & $\begin{array}{c}0.8835^{* * *} \\
(0.000)\end{array}$ & $\begin{array}{c}0.7796^{* * *} \\
(0.000)\end{array}$ & $\begin{array}{c}4.1945^{* * *} \\
(0.000)\end{array}$ & $\begin{array}{c}0.9566^{* * *} \\
(0.000)\end{array}$ & $\begin{array}{c}0.8759^{* * *} \\
(0.000)\end{array}$ & $\begin{array}{c}2.3634^{* * *} \\
(0.000)\end{array}$ \\
\hline $\mathrm{IC}_{s}$ & $\begin{array}{c}1.2002^{* * *} \\
(0.000)\end{array}$ & $\begin{array}{c}8.0895^{* * *} \\
(0.000)\end{array}$ & $\begin{array}{c}5.9571^{* * *} \\
(0.000)\end{array}$ & $\begin{array}{c}1.0465^{* * *} \\
(0.000)\end{array}$ & $\begin{array}{c}8.2904^{* * *} \\
(0.000)\end{array}$ & $\begin{array}{c}7.5749^{* * *} \\
(0.000) \\
\end{array}$ \\
\hline $\mathrm{IC}_{s} 2$ & & $\begin{array}{c}-0.0745^{* * *} \\
(0.000)\end{array}$ & $\begin{array}{c}-0.0467^{* *} \\
(0.000)\end{array}$ & & $\begin{array}{c}-0.0786^{* * *} \\
(0.000)\end{array}$ & $\begin{array}{c}-0.06618^{* * *} \\
(0.000)\end{array}$ \\
\hline $\mathrm{MP} * \mathrm{IC}_{s}$ & & & $\begin{array}{c}-0.0488^{* * *} \\
(0.000)\end{array}$ & & & $\begin{array}{c}-0.0243^{* * *} \\
(0.000)\end{array}$ \\
\hline$R^{2}$ & 0.0673 & 0.0805 & 0.0686 & 0.3690 & 0.3879 & 0.3848 \\
\hline Observations & 2702 & 2702 & 2702 & 2702 & 2702 & 2702 \\
\hline
\end{tabular}

${ }^{*} p<0.1 ;{ }^{* *} p<0.05 ;{ }^{* * *} p<0.01$.

TABLE 6: Regression results of manufacturing share within $100 \mathrm{~km}, 300 \mathrm{~km}$, and $500 \mathrm{~km}, 5$-year periods.

\begin{tabular}{|c|c|c|c|c|c|c|}
\hline & \multicolumn{3}{|c|}{$\mathrm{FE}$} & \multicolumn{3}{|c|}{$\mathrm{RE}$} \\
\hline & $100 \mathrm{~km}$ & $300 \mathrm{~km}$ & $500 \mathrm{~km}$ & $100 \mathrm{~km}$ & $300 \mathrm{~km}$ & $500 \mathrm{~km}$ \\
\hline Pop 1980 & & & & $\begin{array}{c}0.9300^{* * *} \\
(0.000)\end{array}$ & $\begin{array}{c}0.4231^{* * *} \\
(0.000)\end{array}$ & $\begin{array}{c}0.3699^{* * *} \\
(0.000)\end{array}$ \\
\hline MP & $\begin{array}{c}-3.4262^{* *} \\
(0.015)\end{array}$ & $\begin{array}{c}-0.9661^{* *} \\
(0.033)\end{array}$ & $\begin{array}{c}-0.6391^{* *} \\
(0.044)\end{array}$ & $\begin{array}{c}-2.9882^{* *} \\
(0.026)\end{array}$ & $\begin{array}{c}-0.1319 \\
(0.748)\end{array}$ & $\begin{array}{c}-0.0274 \\
(0.923)\end{array}$ \\
\hline $\mathrm{IC}_{m}$ & $\begin{array}{c}-38.8664 \\
(0.035)\end{array}$ & $\begin{array}{c}-3.5145 \\
(0.279)\end{array}$ & $\begin{array}{l}0.3209 \\
(0.837)\end{array}$ & $\begin{array}{c}-34.0701 \\
(0.058)^{*}\end{array}$ & $\begin{array}{l}1.5354 \\
(0.622)\end{array}$ & $\begin{array}{c}2.6761^{*} \\
(0.071)\end{array}$ \\
\hline $\mathrm{IC}_{m} 2$ & $\begin{array}{l}0.2547 \\
(0.105) \\
\end{array}$ & $\begin{array}{c}-0.0013 \\
(0.966)\end{array}$ & $\begin{array}{c}-0.0318^{* *} \\
(0.037) \\
\end{array}$ & $\begin{array}{c}0.1947 \\
(0.202) \\
\end{array}$ & $\begin{array}{c}-0.0442 \\
(0.117) \\
\end{array}$ & $\begin{array}{c}-0.0524^{* * *} \\
(0.000) \\
\end{array}$ \\
\hline $\mathrm{MP} * \mathrm{IC}_{m}$ & $\begin{array}{c}0.1191^{* * *} \\
(0.002)\end{array}$ & $\begin{array}{c}0.0587^{* * *} \\
(0.000)\end{array}$ & $\begin{array}{c}0.0503^{* * *} \\
(0.000)\end{array}$ & $\begin{array}{c}0.0967^{* * *} \\
(0.005)\end{array}$ & $\begin{array}{c}0.0295^{* * *} \\
(0.007)\end{array}$ & $\begin{array}{c}0.0270^{* * *} \\
(0.000)\end{array}$ \\
\hline$R^{2}$ & 0.0460 & 0.0799 & 0.085 & 0.2878 & 0.4105 & 0.411 \\
\hline Observations & 162 & 814 & 1493 & 162 & 814 & 1493 \\
\hline
\end{tabular}

${ }^{*} p<0.1 ;{ }^{* *} p<0.05 ;{ }^{* * *} p<0.01$. 
TABLE 7: Regression results of service share within $100 \mathrm{~km}, 300 \mathrm{~km}$, and $500 \mathrm{~km}$, 5-year periods.

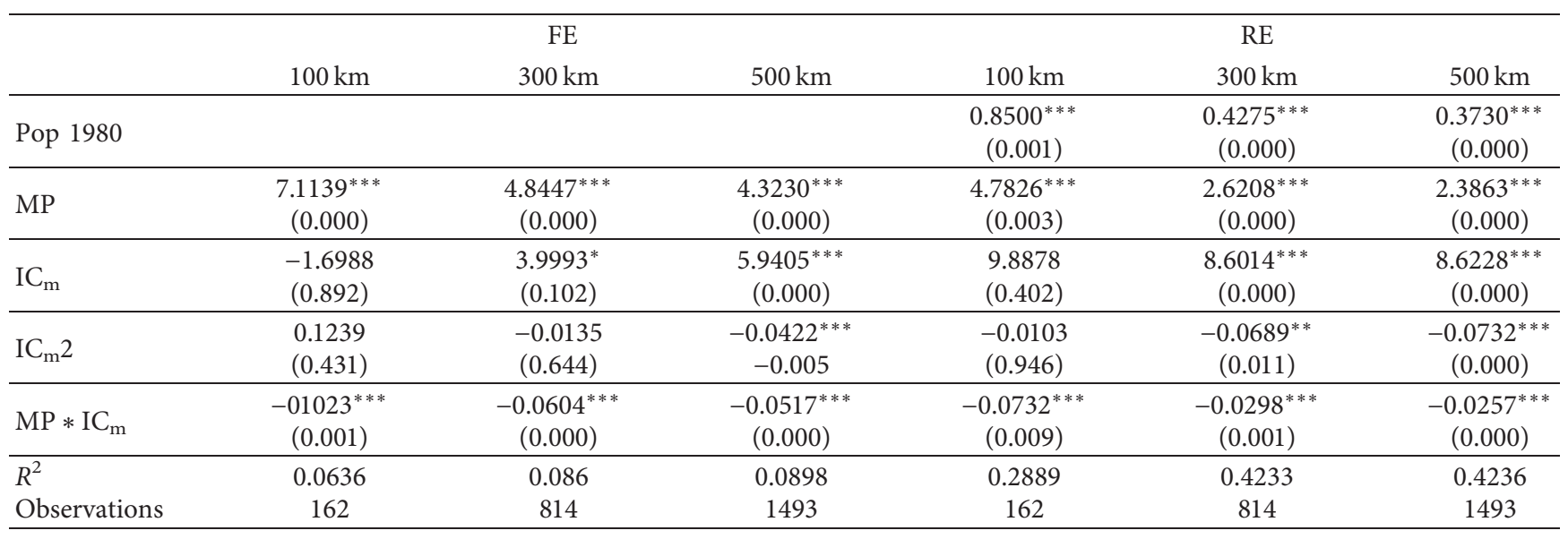

${ }^{*} p<0.1 ;{ }^{* *} p<0.05 ;{ }^{* * *} p<0.01$.

TABLE 8: Comparison between manufacturing and service shares, 10-year periods.

\begin{tabular}{|c|c|c|c|c|c|c|}
\hline & \multicolumn{3}{|c|}{ Manufacturing industry } & \multicolumn{3}{|c|}{ Service } \\
\hline & OLS & FE & $\mathrm{RE}$ & OLS & $\mathrm{FE}$ & $\mathrm{RE}$ \\
\hline Pop 1980 & $\begin{array}{c}0.47010^{* * *} \\
(0.000)\end{array}$ & & $\begin{array}{c}0.4649^{* * *} \\
(0.000)\end{array}$ & $\begin{array}{c}0.4733^{* * *} \\
(0.000)\end{array}$ & & $\begin{array}{c}0.4697^{* * *} \\
(0.000)\end{array}$ \\
\hline MP & $\begin{array}{c}-0.6884 \\
(0.168)\end{array}$ & $\begin{array}{l}0.0984 \\
(0.853)\end{array}$ & $\begin{array}{c}-0.3029 \\
(0.507)\end{array}$ & $\begin{array}{c}2.7118^{* * *} \\
(0.000)\end{array}$ & $\begin{array}{l}2.3016^{*} \\
(0.072)\end{array}$ & $\begin{array}{c}3.4210^{* * *} \\
(0.000)\end{array}$ \\
\hline IC & $\begin{array}{c}14.7264^{* * *} \\
(0.000)\end{array}$ & $\begin{array}{c}12.3713^{* * *} \\
(0.000)\end{array}$ & $\begin{array}{c}11.7761^{* * *} \\
(0.000)\end{array}$ & $\begin{array}{c}17.2413^{* * *} \\
(0.000)\end{array}$ & $\begin{array}{c}15.5607^{* * *} \\
(0.000)\end{array}$ & $\begin{array}{c}15.4540^{* * *} \\
(0.000)\end{array}$ \\
\hline IC2 & $\begin{array}{c}-0.1555^{* * *} \\
(0.000)\end{array}$ & $\begin{array}{c}-0.1471^{* * *} \\
(0.000)\end{array}$ & $\begin{array}{c}-0.1353^{* * *} \\
(0.000)\end{array}$ & $\begin{array}{c}-0.1864^{* * *} \\
(0.000)\end{array}$ & $\begin{array}{c}-0.1578^{* * *} \\
(0.000)\end{array}$ & $\begin{array}{c}-0.1605^{* * *} \\
(0.000)\end{array}$ \\
\hline $\mathrm{MP} * \mathrm{IC}$ & $\begin{array}{l}0.0132 \\
(0.281)\end{array}$ & $\begin{array}{c}-0.0102 \\
(0.593)\end{array}$ & $\begin{array}{c}0.0317^{* * *} \\
(0.009)\end{array}$ & $\begin{array}{c}-0.0283^{* *} \\
(0.010)\end{array}$ & $\begin{array}{c}-0.0344^{* *} \\
(0.045)\end{array}$ & $\begin{array}{c}-0.0439^{* * *} \\
(0.000)\end{array}$ \\
\hline$R^{2}$ & 0.3591 & 0.0016 & 0.3559 & 0.3736 & 0.0486 & 0.3721 \\
\hline Observations & 2702 & 2702 & 2702 & 2702 & 2702 & 2702 \\
\hline
\end{tabular}

${ }^{*} p<0.1 ;{ }^{* *} p<0.05 ;{ }^{* * *} p<0.01$.

initial population is also stronger for both industries over 10 years. It means that Gibrat's law is rejected for China. These findings are consistent with some existing studies [45, 46].

\section{Discussion}

China's rapid industrialization since 1978 has seen important transformation in the economic base of its cities. As the world's largest factory, much of its rise in the past three decades has rested on a vibrant manufacturing sector that churns out textiles and apparel, electronics, and computers for the rest of the world. So, the results make intuitive sense: China's urban population growth has exploded as China emerged as the world's manufacturing center. While attention on the service sector has no doubt continued to fuel the growth of cities around core ones, the random effect model result raises the question if such growth will persist with continued expansion. These results would seem to be consistent with Burger et al.'s findings [8] which showed that the shift to consumer services in Northwest Europe's consumer cities has limited positive spillover on surrounding cities.
Likewise in China, rising consumption in the service sector and producer services like finance and accounting remains highly clustered in core cities. In addition, the interaction variable $\mathrm{MP} \times \mathrm{IC}$ indicates that the effect of manufacturing share on market potential and population growth of surrounding cities is positive while that of services is negative.

The results could explain why Beijing has a greater potential to cast an agglomeration shadow compared to the urban systems in the Yangtze River Delta and Pearl River Delta $[47,48]$. Beijing has placed excessive focus on serviceled development, and this has reduced the geographical spillover effects of the city compared to other core cities. Even by 2015, the share of manufacturing in Shanghai and Guangzhou is still more than 10 percentage points lower than that in Beijing. The results also support studies in developed countries. Studies have found that the role of major US cities is insignificant, or at least not robust, in relation to the growth of other cities $[18,20,47]$. With deindustrialization in the late of twentieth century, the service sector has dominated in most major US cities followed by reduced spillover effect. 


\section{Summary and Conclusions}

The empirical analysis in this paper tests the relationship between industrial composition and population growth of cities around core cities. It provides some evidence that for core cities, manufacturing rather than service overall encourages the growth of surrounding cities by providing spillover. However, importantly, industrial composition per se does not directly impact surrounding cities; it exerts the effect through market potential. The reasons behind are related to a myth in urban field-why cities form and grow at varying rates. The works of Paul Krugman $[12,13]$ added important spatial insights to this question. He has identified two fundamental features-the first and second natures. In brief, the first nature features are those that are intrinsic to the site itself, such as favorable climates, while the second nature features of a location are those that are impacted by the spatial structure of the economic system. The impact of economic system implies the second nature depends on economic links between two cities. It is different link models between manufacturing and service that contribute to various impacts of industrial composition on market potential. In other words, industrial composition in core cities impacts the growth of surrounding cities via the second nature.

Specifically, for the development of manufacturing sectors in core cities, regional production networks are usually required. Due to transportation cost, this production networks generally develop around the core cities. It means manufacturing development follows the rule of contagious diffusion. In this way, core cities can be seen to have boosted the cities around them by promoting production networks. However, for service sectors, the situation is completely different. Time cost is more important for service sectors than transportation cost. Small cities around top-tier cities do not have significant advantages than those second-level cities far away from top-tier cities, in the view of time cost either induced by business travels by aircraft or communication by Internet. Importantly, second-level cities have bigger markets than small cities. So, service sectors tend to transfer from top cities to second-level cities rather than small cities close to them. It means service development follows the rule of hierarchical diffusion. The spatial spillover effects of service sectors are weak to those cities close to core cities.

Even so, the shares of manufacturing and service express an inverse $U$ relationship so that low and high shares are less positive for the population growth of surrounding cities. Various coefficients indicate that the peak is different for industry and service. Investigations from three spatial scales confirm the difference of locations of the peaks between industry and service. The peak for service is $100-300 \mathrm{~km}$ away from core cities, while for industry, it is about $300 \mathrm{~km}$ or more away from core cities. More importantly, together with hierarchical diffusion, relatively smaller distance between the peak for service and core cities probably means there is more than one peak in a large region. Actually, when adding a cubic term in the model, the effect is still significant for service, while for industry, the effect is insignificant. So, for industry, leading force from core cities decreases with distance after the peak. It is in line with the characteristic of contagious diffusion.

\section{Data Availability}

The study employed population data of Chinese cities from 1950 to 2015 to investigate difference in growth among cities. The population data used to support the findings of this study have been deposited in the repository of World Urbanization Prospects from United Nations, Department of Economic and Social Affairs, Population Division (https:// www.un.org/en/development/desa/population/index.asp).

\section{Conflicts of Interest}

The authors declare that they have no conflicts of interest.

\section{Acknowledgments}

This work was supported by The Second Scientific Investigation of the Tibetan Plateau (Grant no. 2019QZKK0406) and the National Natural Science Foundation of China (Grant no. 41701128).

\section{References}

[1] K. Wem and E. Zhu, Report on Development of Beijing, Tianjin and Hebei Province, Springer, New York, NY, USA, 2015.

[2] D. Zhu, "New urbanization: theory, challenges and research," in Cities in the Twenty-First Century, O. M. Nel-lo, Ed., Routledge, London, UK, 2016.

[3] M. D. Partridge, D. S. Rickman, K. Ali, and M. R. Olfert, "Do New Economic Geography agglomeration shadows underlie current population dynamics across the urban hierarchy?" Papers in Regional Science, vol. 88, no. 2, pp. 445-466, 2009.

[4] M. Fujita and P. Krugman, "When is the economy monocentric?: von Thünen and Chamberlin unified," Regional Science and Urban Economics, vol. 25, no. 4, pp. 505-528, 1995.

[5] P.-P. Combes and H. G. Overman, "Chapter 64 the spatial distribution of economic activities in the European Union," Handbook of Regional and Urban Economics, vol. 4, pp. 2845-2909, 2004.

[6] W. Alonso, "Urban zero population growth," Daedalus, vol. 102, no. 4, pp. 191-206, 1973.

[7] E. J. Meijers and M. J. Burger, "Stretching the concept of "borrowed size"” Urban Studies, vol. 54, no. 1, pp. 269-291, 2017.

[8] M. Burger, E. Meijers, M. Hoogerbrugge, and J. \&Tresserva, "Borrowed size, agglomeration shadows and cultural amenities in North West Europe[J]," European Planning Studies, vol. 23, no. 6, pp. 1190-1109, 2015.

[9] K. Ikeda, K. Murota, T. Akamatsu, and Y. Takayama, “Agglomeration patterns in a long narrow economy of a new economic geography model: analogy to a racetrack economy," International Journal of Economic Theory, vol. 13, no. 1, pp. 113-145, 2017.

[10] M. Fujita, P. Krugman, and A. \&Venables, The Spatial Economy: Cities, Regions and International Trade, MIT Press, Cambridge, MA, USA, 1999. 
[11] C. D. Harris, "The, market as a factor in the localization of industry in the United States," Annals of the Association of American Geographers, vol. 44, no. 4, pp. 315-348, 1954.

[12] P. Krugman, "On the number and location of cities," European Economic Review, vol. 37, no. 2-3, pp. 293-298, 1993.

[13] P. Krugman, "Increasing returns and economic geography," Journal of Political Economy, vol. 99, no. 3, pp. 483-499, 1991.

[14] P. Krugman, "First nature, second nature, and metropolitan location," Journal of Regional Science, vol. 33, no. 2, pp. 129-144, 1993.

[15] M. Fujita and T. Mori, "Structural stability and evolution of urban systems," Regional Science and Urban Economics, vol. 27, no. 4-5, pp. 399-442, 1997.

[16] M. Fujita, P. Krugman, and T. Mori, "On the evolution of hierarchical urban systems," European Economic Review, vol. 43, no. 2, pp. 209-251, 1999.

[17] D. Black and V. Henderson, "Urban evolution in the USA," Journal of Economic Geography, vol. 3, no. 4, pp. 343-372, 2003.

[18] L. H. Dobkins and Y. M. Ioannides, "Spatial interactions among US cities: 1900-1990," Regional Science and Urban Economics, vol. 31, pp. 701-731, 2001.

[19] T. Mori, "A modeling of megalopolis formation: the maturing of city systems," Journal of Urban Economics, vol. 42, no. 1, pp. 133-157, 1997.

[20] Y. M. Ioannides and H. G. Overman, "Spatial evolution of the US urban system," Journal of Economic Geography, vol. 4, no. 2, pp. 131-156, 2004.

[21] M. Fujita and T. Mori, "Frontier of the New Economic Geography," Institute of Developing Economies, Wakaba-Chiba, Japan, Discussion Paper 27, 2005.

[22] S. Pinch and N. Henry, "Paul krugman's geographical economics, industrial clustering and the British motor sport industry," Regional Studies, vol. 33, no. 9, pp. 815-827, 1999.

[23] U. Kaiser, Innovation, Employment, and Firm Performance in the German Service sector, Springer Science \& Business Media, Heidelberg, Germany, 2002.

[24] U. Kaiser, "Measuring knowledge spillovers in manufacturing and services: an empirical assessment of alternative approaches," Research Policy, vol. 31, no. 1, pp. 125-144, 2002.

[25] T. Mori, K. Nishikimi, and T. E. Smith, "On the identification of industrial agglomerations and their spatial coordination," in Progress, Institute of Economic Research, Kyoto University, Kyoto, Japan, 2005.

[26] J. Li, T. Sun, and W. Zhang, "Spatial cluster characteristics and modes of producer services in China," Scientia Geographica Sinica, vol. 34, pp. 385-393, 2014.

[27] M. Storper and T. Venables, "Buzz: face-to-face contact and the urban economy," Journal of Economic Geography, vol. 4, no. 4, pp. 351-370, 2003.

[28] E. Ghoul, O. Guedhami, Y. Ni, J. Pittman, and S. Saadi, "Does information asymmetry matter to equity pricing? Evidence from fimrs' geographic location," Contemporary Accounting Research, vol. 30, no. 1, pp. 140-181, 2013.

[29] R. Thomadsen, "Product positioning and competition: the role of location in the fast food industry," Marketing Science, vol. 26, no. 6, pp. 792-804, 2007.

[30] E. L. Glaeser and J. E. Kohlhase, "Cities, regions and the decline of transport costs," Fifty Years of Regional Science, vol. 83, pp. 197-228, 2004.

[31] M. Zhao, X. Liu, B. Derudder, Y. Zhong, and W. Shen, "Mapping producer services networks in mainland Chinese cities," Urban Studies, vol. 52, no. 16, pp. 3018-3034, 2015.
[32] A. Yeh and F. Yang, "Introduction and overview," in Producer Services in China: Economic and Urban Development, A. Yeh and F. Yang, Eds., ROutledge, London, UK, 2013.

[33] A. M. Herrmann, J. L. Taks, and E. Moors, "Beyond regional clusters: on the importance of geographical proximity for $\mathrm{R} \& \mathrm{D}$ collaborations in a global economy-the case of the flemish biotech sector," Industry \& Innovation, vol. 19, no. 6, pp. 499-516, 2012.

[34] H. Tervo, "Cities, hinterlands and agglomeration shadows: spatial developments in Finland during 1880-2004," Explorations in Economic History, vol. 47, no. 4, pp. 476-486, 2010.

[35] J. Eeckhout, "Gibrat's Law for (all) cities," American Economic Review, vol. 94, no. 5, pp. 1429-1451, 2004.

[36] T. Tabuchi and J.-F. Thisse, "Regional specialization, urban hierarchy, and commuting costs," International Economic Review, vol. 47, no. 4, pp. 1295-1317, 2006.

[37] Z. Chen, M. Lu, and Z. Xu, "Agglomeration shadow: a nonlinear core-periphery model of urban growth in China 1990-2006," in Proceedings of the ADB Workshop on Green Urbanization in Asia, Honolulu, Hawaii, 2001.

[38] M. Chen, W. Liu, and X. Tao, "Evolution and assessment on China's urbanization 1960-2010: under-urbanization or overurbanization?” Habitat International, vol. 38, pp. 25-33, 2013.

[39] G. C. S. Lin, "Small town development in socialist China: a functional analysis," Geoforum, vol. 24, no. 3, pp. 327-338, 1993.

[40] National Bureau of Statistics of China, China Statistical Yearbook, National Bureau of Statistics of China, Beijing, China, 2016.

[41] M. Fragkias and K. C. Seto, "Evolving rank-size distributions of intra-metropolitan urban clusters in South China," Computers, Environment and Urban Systems, vol. 33, no. 3, pp. 189-199, 2009.

[42] K. Li and B. Lin, "The nonlinear impacts of industrial structure on China's energy intensity," Energy, vol. 69, pp. 258-265, 2014.

[43] M. Bosker and E. Buringh, "City seeds: geography and the origins of the European city system," Journal of Urban Economics, vol. 98, pp. 139-157, 2010.

[44] M. Storper and A. J. Scott, "Rethinking human capital, creativity and urban growth," Journal of Economic Geography, vol. 9, pp. 147-167, 2009.

[45] K. T. Soo, "Zipf, Gibrat and geography: evidence from China, India and Brazil," Papers in Regional Science, vol. 93, no. 1, pp. 159-181, 2014.

[46] J. P. Chauvin, E. Glaeser, Y. Ma, and K. Tobio, "What is different about urbanization in rich and poor countries? Cities in Brazil, China, India and the United States," Journal of Urban Economics, vol. 98, pp. 17-49, 2017.

[47] D. Sun, J. Zhang, Y. Hu, L. Zhou, and Z. Yu, “The formation of metropolitan shadow from the perspective of industry spatial contacts: a comparison between changjiang River Delta and beijing-tianjin-hebei metropolitan region," Scientia Geographica Sinica, vol. 47, pp. 1295-1317, 2013.

[48] C. Li, K. Wu, and X. Gao, "Manufacturing industry agglomeration and spatial clustering: evidence from Hebei Province, China," Environment, Development and Sustainability, vol. 22, no. 4, pp. 2941-2965, 2019.

[49] M. D. Partridge, "The duelling models: NEG vs amenity migration in explaining US engines of growth," Papers in Regional Science, vol. 89, no. 3, pp. 513-536, 2010. 